\title{
EL DESEO SEXUAL, LA FANTASÍA NARCISISTA Y LA VIOLENCIA
}

Amaya Ortiz de Zárate

\section{Resumen}

La construcción de una representación simbólica de lo femenino es uno de los problemas urgentes de la cultura de nuestro tiempo.

Las relaciones amorosas ponen en juego todas las fantasías en las que se sostiene la identidad intersubjetiva: comunicativa: dual.

Pero afrontar la relación sexual supone antes o después ser defraudado por el objeto fascinante puesto en juego en el escenario de la seducción.

Saber atravesar ese momento es el saber propio de lo femenino en el lance del cortejo.

La mujer cita y se ofrece como objeto de deseo, consciente de que lo que ofrece al yo es la muerte.

Si lo consigue, el deseo narcisista atraviesa el espejo y el Sujeto puede hacer una experiencia del Otro real -el otro sexo.

Si fracasa, el amante capturado en el juego de reflexión de los espejos, puede optar por quebrarlo.

Palabras Clave: simbólica de lo femenino, deseo narcisista, deseo sexual, violencia

\begin{abstract}
The construction of a symbolic representation of the feminine is an urgent task our culture is required to face up. Love relationships cause all fantasies supporting communicative, dual intersubjectivity to come into play. Yet, facing up sexual relations results, soon or later, in the disappointment about the fascinating object staged within the seduction secene. How to manage to go through such situation is a distinctive knowledge belonging to feminine that intervenes in courtship. Being aware that they offer the Ego the Death, women incite, and offer themselves as being the object of desire. If they succeed, then the narcissistic desire will cross the mirror, and it will be possible for the Subject to experience the real Other, i.e., the other sex. If she fails, the lover, captured in the net of mirror reflections, may opt to break the mirror.
\end{abstract}

Key Words: Symbolic representations of the feminine. Narcissistic desire. Sexual desire.Violence. 


\section{Educación en Valores}

Una de las estrategias que mayor interés concitan entre los expertos dedicados al problema de la violencia es la intervención preventiva, en el ámbito educativo, en torno a lo que se ha denominado "Educación en Valores".

Es incesante la aparición de publicaciones, programas de intervención y cursos para especialistas que pretenden incidir en la prevención del maltrato y la violencia, además de los programas diseñados específicamente para la reeducación de maltratadores y víctimas.

Y sin embargo, pese a la anuencia en que la educación en valores es una acuciante necesidad para erradicar la violencia, la enfermedad e incluso la pobreza, seguimos confiando ingenuamente en que la tarea podrá ser realizada mediante el expediente de transmitir ciertos conceptos por medio del desarrollo de programas específicos o de la implantación en los curricula escolares de asignaturas nuevas.

Confianza excesiva porque, de hecho, cada uno de los agentes implicados educadores, trabajadores sociales, sanitarios, psicólogos, sexólogos, filósofos, expertos en bioética, etc.-, sabe, en tanto depositario de ciertos valores, que estos proceden de determinados actos de transmisión en los que es parte fundamental la relación que el educador establece con aquello que transmite y con aquellos a quienes lo transmite.

Y ello, porque lo que corresponde propiamente al valor ético de lo aprendido es de carácter práctico y evaluativo -en cuya determinación interviene siempre un componente afectivo-. Debido a que lo que está en juego es el discernimiento entre lo que está bien y lo que está mal, no de un modo virtual o puramente abstracto, sino en el contexto situacional en el que se desenvuelve la experiencia de cada uno.

De lo que se derivan dos consecuencias. La primera, que la actividad implícita en la adquisición de valores excede del mero uso de procesos cognitivos, es decir, racionales, y requiere también de una actividad del juicio ético que pone en juego la pasión -y la compasión- de cada sujeto. La segunda, que ese aprendizaje precisa por tanto no sólo la comprensión de ciertos contenidos o el entrenamiento en ciertas 
habilidades por parte del que los adquiere, sino también, necesariamente, de un acto de transmisión en el que el educador, investido de cierta autoridad en lo que hace, practica los valores que pretende transmitir.

Por ejemplo, podremos transmitir mucho mejor una noción general de respeto si podemos definirla en un contexto práctico de respeto mutuo.

\section{Violencia}

Quizá convenga reflexionar por un momento acerca de la general sordera emocional, es decir, la incapacidad para percibir las emociones, que padece nuestra cultura occidental moderna, y que afecta especialmente a la capacidad para percibir o concebir siquiera la posibilidad de la violencia. Una violencia que sigue sorprendiéndonos, cuando aparece, por no decir que nos deja estupefactos.

$\mathrm{Y}$ es que de acuerdo con la premisa fundamental de la concepción ilustrada, alumbrada ya en Descartes, la naturaleza humana sería de carácter racional. Consecuentemente, uno de los fundamentos del proyecto cultural occidental ha consistido en desterrar por completo la violencia del campo de las relacione humanas, una vez convenientemente ordenadas mediante un aprendizaje correcto. Y una vez desautorizada la violencia, es posible relegarla al campo de las otras especies, épocas, o culturas, como un cuerpo extraño, cuya sola evidencia sirve mejor para negar la propia.

Una concepción reconfortante, sin duda, cuya contrapartida es nuestra renuncia a gobernarla. De ahí que cuando, pese a todo, la violencia irrumpe desordenadamente, sólo podamos juzgarla disfuncional o inútil -en el mejor de los casos-, cuando no como una conducta patológica. Y sin embargo, ese mismo proyecto ilustrado que relegó la violencia a la trastienda de los viejos enseres, alumbró una de las concepciones de la mente humana más poderosas de todos los tiempos.

Fue Sigmund Freud quien realizó el pasaje desde un concepto de inconsciente regido sólo por el instinto -vestigio de nuestro pasado evolutivo- al de un inconsciente más allá de lo reprimido, consistente en pura energía. 
La pulsión, a partir de 1920 (“Más allá del Principio del Placer”), tanto más cuanto más avanza su teoría, consiste para Freud solamente en eso: energía no ligada a ningún estímulo, que habrá de ser conducida por los cauces de las operaciones simbólicas a su transformación en deseo: energía ligada a representaciones del mundo los objetos-.

\section{El espectáculo televisivo}

$\mathrm{Si}$, como argumentamos, la transmisión de valores se produce no sólo en el ámbito conceptual, sino también y fundamentalmente en el de la acción, a través del poder performativo de los actos de lenguaje, no deberíamos desestimar el poder formativo de los modelos ofrecidos por los comunicadores en el más potente generador de discurso contemporáneo, el medio televisivo.

Un niño de 6 años, en cualquiera de nuestras sociedades, ha visto ya, de promedio, un año de programación televisiva.

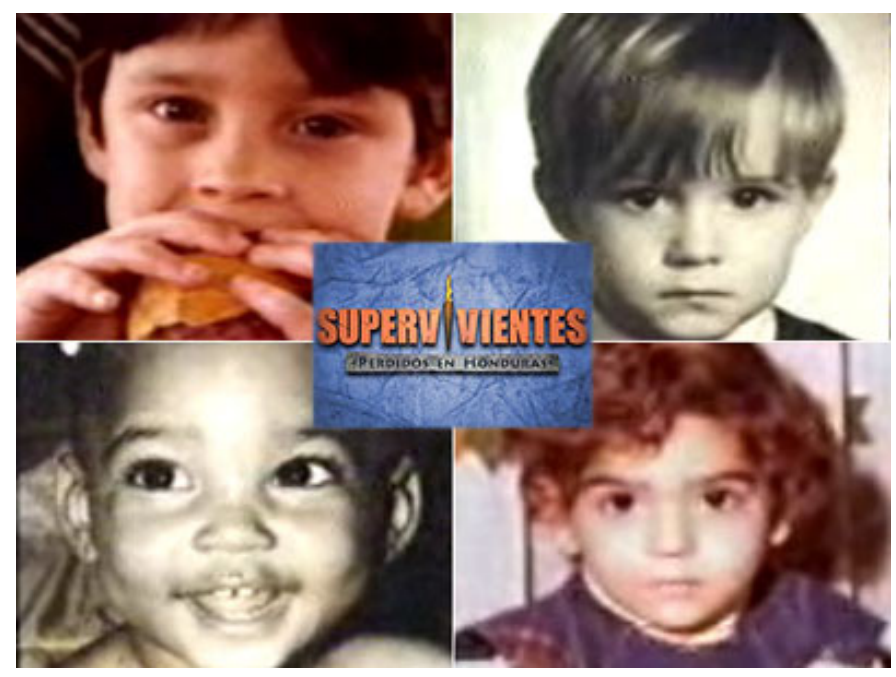

Imagen 1

Cuestiones de género, 2008, nº 3, pp 
Y existe evidencia suficiente como para saber que el consumo televisivo correlaciona positivamente con trastornos como la obesidad o el insomnio, y negativamente con el rendimiento escolar. (Archives of Pediatrics \& Adolescent Medicine Vol. 159 No 7 July. 2005; 619-625)

Las cifras coinciden una y otra vez en señalar que los niños, que han desaparecido de forma generalizada como público especifico para productores y programadores, consumen una media de tres horas diarias de televisión. Una tendencia que no ha dejado de aumentar en nuestro país en la última década. (Cáceres Zapatero, 2006).

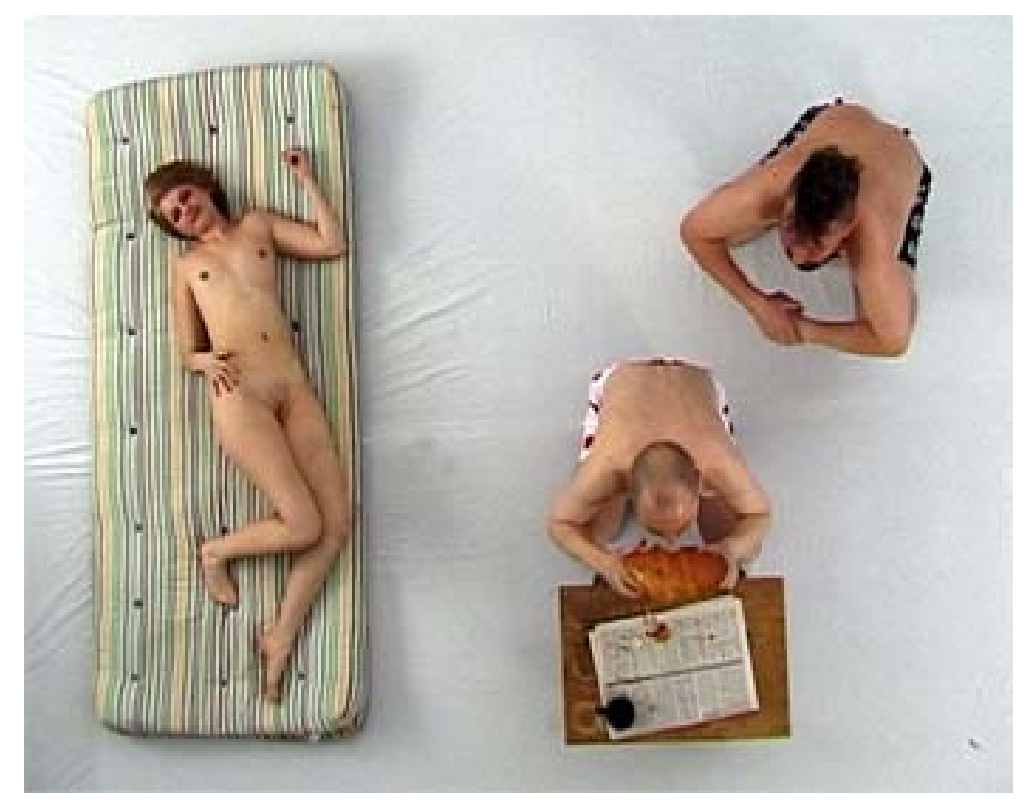

Imagen 2

De modo que puesto que las horas de exposición al medio aumentan, al tiempo que los contenidos educativos disminuyen, lo que los niños consumen indiscriminadamente es la programación habitual en las cadenas abiertas, lo que se ha denominado programación basura. Acertadamente, pues lo que en estas cadenas se 
ofrece a todas horas es el espectáculo de la fragmentación y la basura. Un nuevo circo en el que el entretenimiento de moda consiste en una abierta vejación de la dignidad de las víctimas.

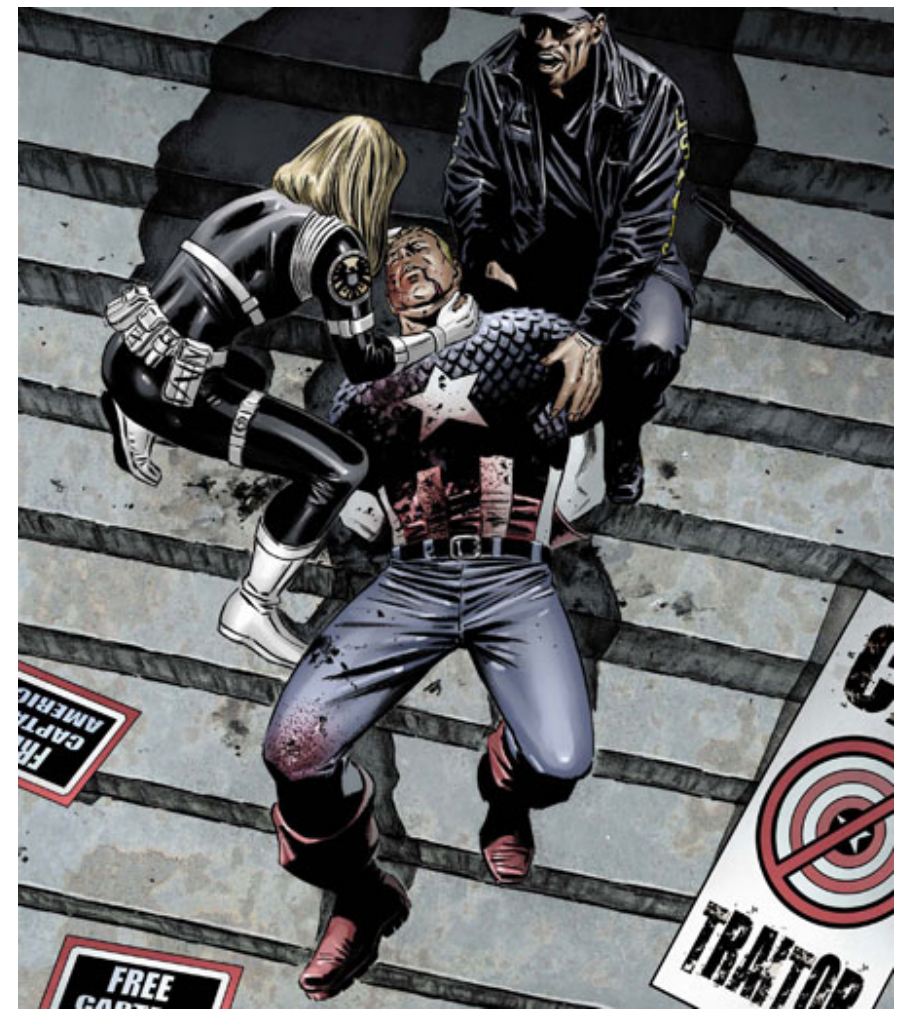

Imagen 3

Si consideramos que el respeto al otro es el valor fundamental para contener la violencia que podría suponer el disfrute ilimitado, meramente pulsional, que es posible obtener del otro, convendremos en que lo que se enseña por esta vía no es lo más adecuado para fomentar una buena convivencia. 


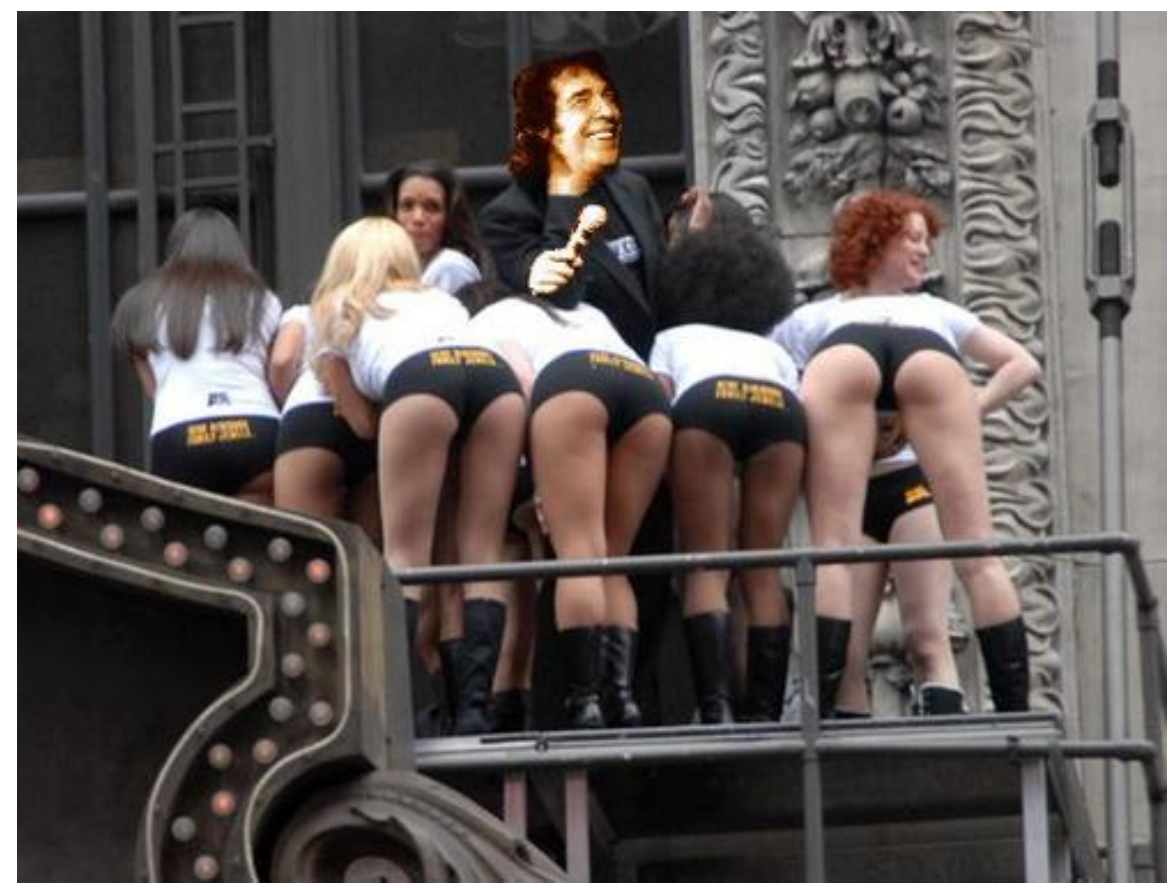

Imagen 4

La coartada frecuentemente esgrimida, el que las víctimas sean voluntarias o incluso remuneradas, no disminuye un ápice la crudeza del espectáculo; por el contrario, contribuye a aumentar, si cabe, sus tintes perversos. Lo que se percibe es el disfrute de toda una colectividad en esa trasgresión progresiva de los límites, sin límite, que resulta violenta.

Si esto es evidente, a poco que se reflexione sobre ello, tendremos que concluir que resulta más rentable incluir asignaturas en los planes de estudios que ejercer un control efectivo sobre los formatos y contenidos de la programación televisiva. 


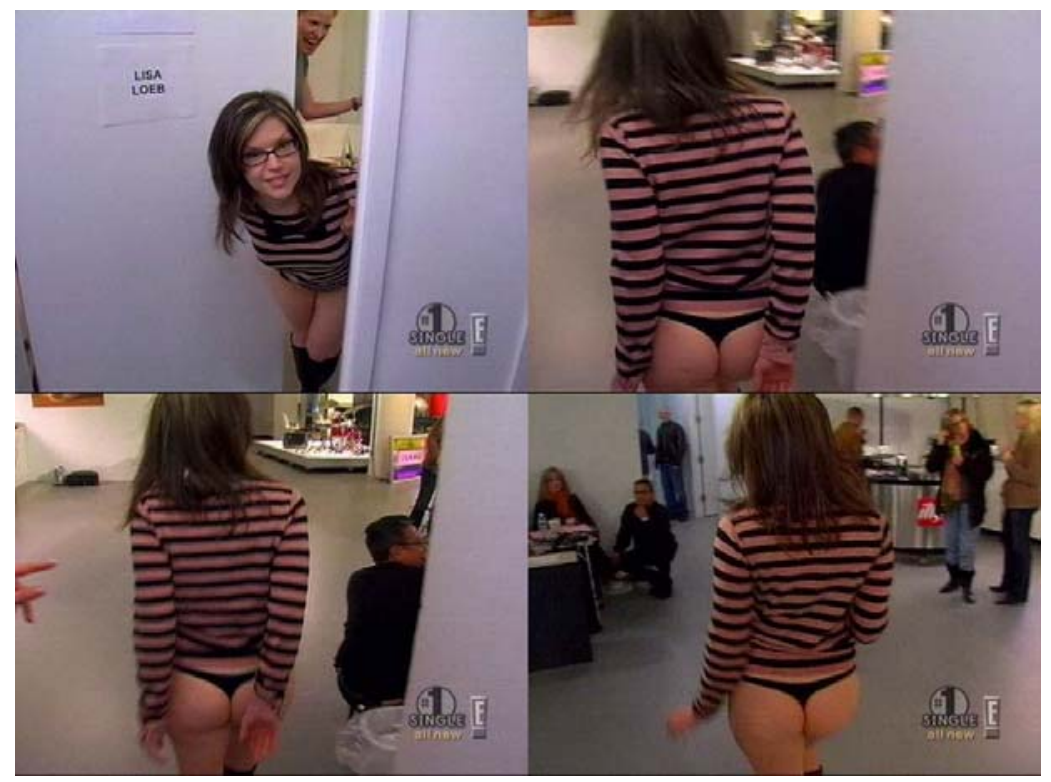

Imagen 5

Actualmente, en España, sólo una cadena, la 2 de televisión española, respeta los acuerdos de autorregulación europeos suscritos hace un año, que restringen la emisión de programación basura en las horas de máxima audiencia infantil.

Para el resto de las cadenas imperan las reglas de la competencia por la cuota de mercado, y el compromiso firmado es papel mojado.

La estética televisiva del Reality Show se ha impuesto, además, contundentemente en el resto de los formatos audiovisuales, invadiendo con sus estilemas característicos el mundo de los video-juegos, la animación para niños, el video-clip, las revistas de belleza y moda, la publicidad, y algunas propuestas pretendidamente artísticas. 


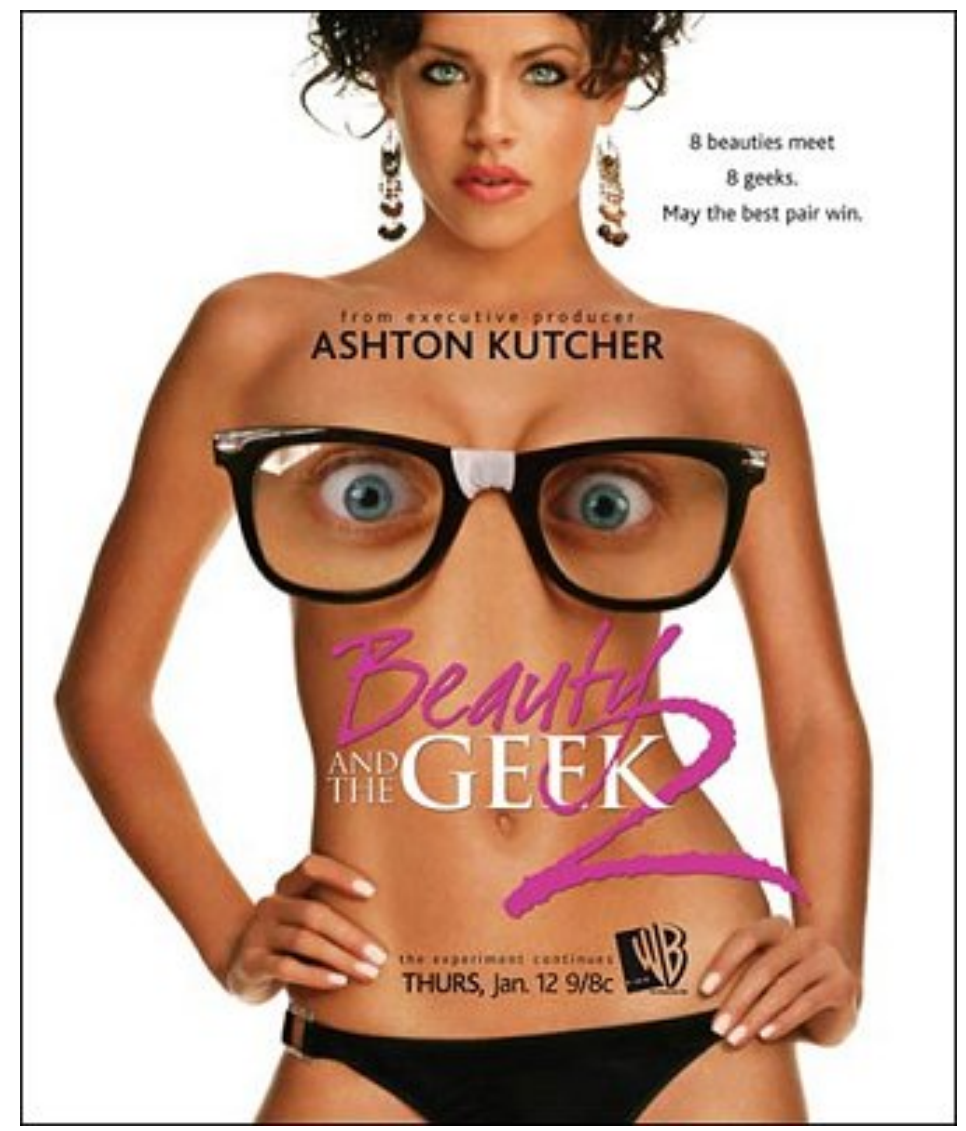

Imagen 6

La administración delega en los padres la imposible tarea de impedir que sus hijos participen de los reality shows -o en sus versiones maquilladas que hemos denominado talk shows- con los que se alimenta su programación en cualquier franja horaria.

¿Ejercicio de hipocresía?

Una cosa puede ser educar a niños y adolescentes y otra, al parecer muy diferente, abordar la educación misma de los educadores. 


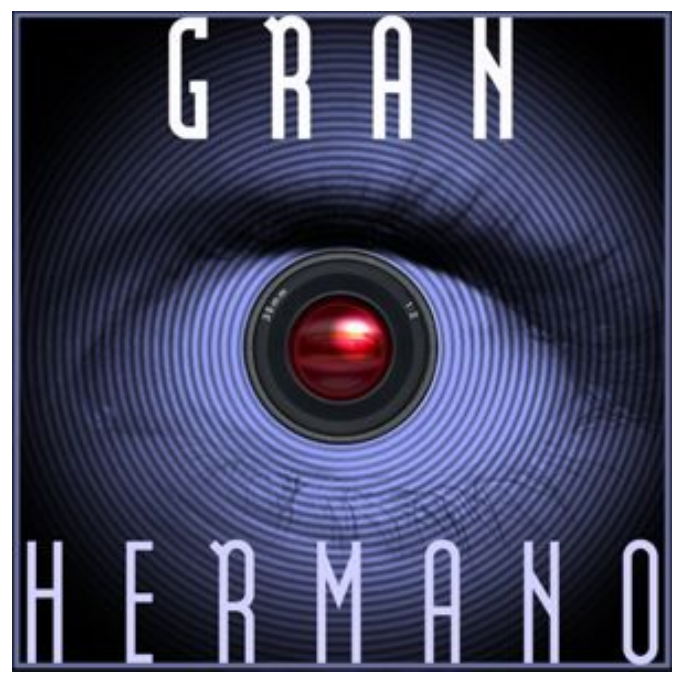

Imagen 7

La reflexión debería comenzar por analizar el tipo de disfrute -consistente, básicamente, en el avasallamiento de la intimidad del otro- ofrecido por el espectáculo del entretenimiento contemporáneo.

Un espectáculo en el que, de entrada, casi nadie reconoce participar abiertamente, aun cuando todos sabemos que su disfrute es "familiar" y masivo.

\section{Te doy mis ojos}

Pero no se trata, desde luego, de enfrentarse a los hechos para convertirlos en piedra de escándalo. Porque a nadie se le escapa que no resulta nada sencillo aprender a desear ni, aún menos, aprender a amar -lo que podría ser objeto de una nueva asignatura, la educación sentimental. 
Podríamos intentar formular la dificultad como pregunta: ¿Es posible amar, sin que ello signifique tan sólo desear la absoluta posesión del objeto?

Cuando hablamos de violencia contra las mujeres -violencia de género es el eufemismo más utilizado- no debemos olvidar que hablamos también de ciertas relaciones amorosas en las que se pone en juego una exigencia de posesión que va más allá de la posesión sexual.

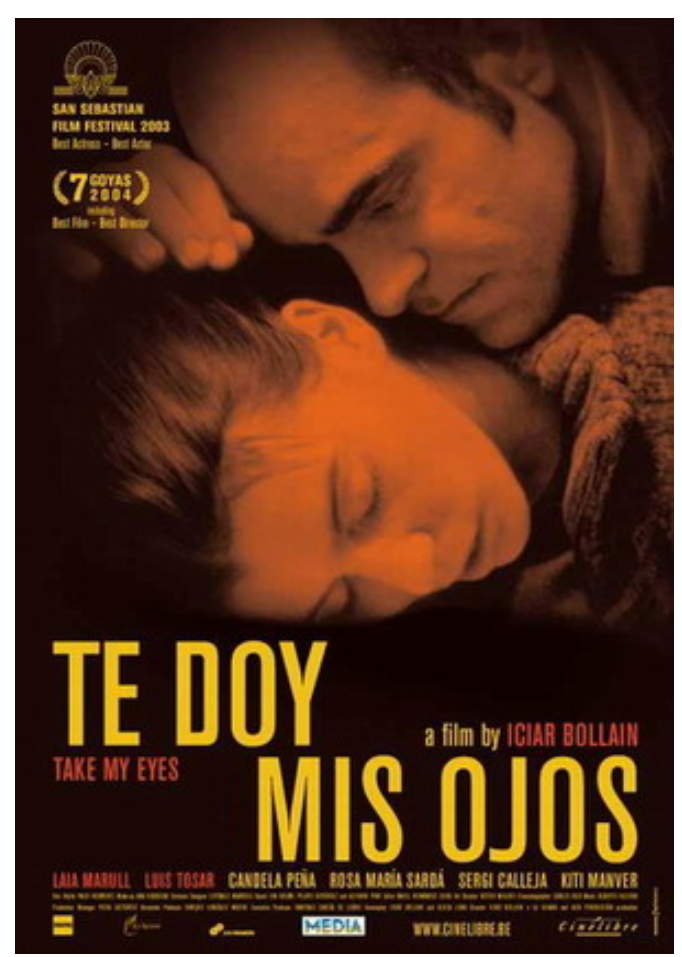

Imagen 8

Porque lo que la magnitud de esa violencia manifiesta, es que algo de la supervivencia misma del amante está en cuestión. De ahí que el momento crítico, el de máximo riesgo, sea siempre el del abandono o la ruptura de la relación. 
El film de Icíar Bollaín, "Te doy mis ojos” - cuyo título es también, en esencia, el contenido del diálogo central de la película en el que se muestra la relación íntima de la pareja- explicita la oferta que la amada -ser poseído, pero también, deseado- hace a su amante. Una oferta en la que los ojos sirven de metonimia a la mirada.

Pero la mirada es uno de los mejores exponentes del punto de vista subjetivo, en el que se cifra la diferencia radical de cada uno. De modo que cuando lo ofrecido es la mirada, la oferta sobrepasa ampliamente la demanda propia de un deseo de posesión sexual -que supondría reconocer la existencia del otro, si no como Sujeto diferente, sí, al menos, como el Otro sexo.

Una oferta que la amante sostiene para satisfacer la demanda de total posesión de cada parte de su cuerpo, y aún más, de su mirada, tradicionalmente prerrogativa del alma. Exigencia del amado que, en el extremo, y de ser satisfecha, negaría el reconocimiento de toda diferencia.

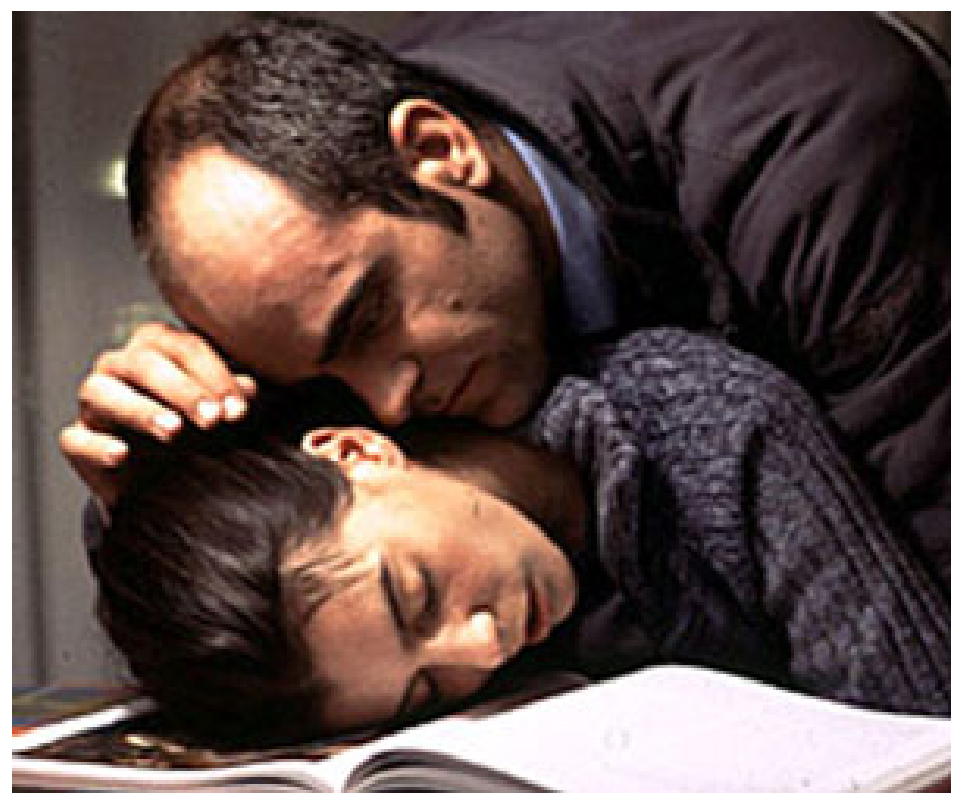

Imagen 9 


\section{Deseo}

De hecho, hay pocas cosas tan escurridizas y tremendamente paradójicas como el deseo humano. Con el término deseo nos referimos, generalmente, a la intencionalidad característica de todo acto psíquico -es decir, dirigido a objeto.

Un objeto que virtualmente puede adoptar todas las formas, porque el deseo nombra en realidad, en su acepción más amplia, la energía con la que investimos la realidad del mundo, es decir, nuestro mundo. Una realidad construida con el conjunto de las representaciones de lo real -de lo que hay-, entretejidas por la trama del deseo.

Deseo es por eso sinónimo de sueño y de ilusión, pero también de lo que se concibe, reconoce y espera. Ese tejido de representaciones que posibilita la conciencia, sirve también para capturar nuestra propia energía tal y como se produce en el origen, libre de toda ligadura, como pulsión. La fuente de la energía psíquica que alimenta las acciones voluntarias, los deseos y los sueños, es por tanto el sistema de representaciones del yo.

\section{Deseo Sexual}

Pero si decimos "el deseo" la connotación se hace explícitamente sexual. El deseo sexual, en singular, se opone a la pluralidad de los deseos.

Cuando nos referimos al deseo sexual, ya no es del yo de donde procede. Porque el deseo hacia el Otro sexual es siempre, también, contra el yo, cuya lógica es la de la inclusión y apropiación de los objetos como una más de las posibles regiones del mundo capturadas por la representación.

\section{Deseo del Yo}

La construcción del yo tiene lugar en una relación dual con el primer objeto deseado, que es antes que nada objeto de identificación. 
Freud denominó a esta modalidad de relación narcisismo primario, retomando el mito de Narciso, que narra el enamoramiento del hijo de una ninfa de una imagen de sí mismo reflejada en el agua, tomándola equivocadamente por la imagen de otro.

Lacan desarrolló la idea con su teorización sobre la génesis del yo en el estadío del espejo, metáfora de la construcción de la primera identidad del niño a través de la mirada de la madre en su reconocimiento del hijo.

Una identidad basada, por tanto, en el deseo de la madre, que suele hacer el papel de ese primer otro para el niño, cuya identidad se construye no sólo por identificación con el objeto deseado sino, y sobre todo, -nueva vuelta de tuerca- con el deseo de ese otro.

La identidad del yo se aprehende, en el origen -de los 6 a los 18 meses-, en la mirada de la madre, en la que el niño se reconoce como en un espejo.

En el período inmediatamente posterior, el yo se inserta en el sistema del lenguaje, que mediará en adelante su vínculo con el otro, y su dominio del mundo. Merced al carácter representacional de este instrumento, las cosas podrán ser sustituidas por sus nombres, y los nombres pasarán a formar parte del conjunto de lo que el yo puede llamar su mundo, sus posesiones.

En otros términos, todo lo que el yo desea, es lo que de un modo u otro puede ser asimilado: representado y anticipado a voluntad. Y lo desea todo, sin exclusión ni límite, ya que su particular lógica es la identificación. Lo que explicaría algo que constituye una evidencia, la dificultad para sostener un deseo propiamente sexual -es decir, dirigido a Otro diferente, que no es yo. ¿De dónde procede, entonces, ese deseo sexual, o el Deseo con mayúscula?

\section{Deseo del Sujeto}

Digamos que procede del inconsciente $\mathrm{o}$, más propiamente, que quien lo sostiene es el Sujeto del inconsciente.

Cuestiones de género, 2008, $n^{\circ}$ 3, pp 
Su lógica ya no es la identificación, sino todo lo contrario, la derivada de la inscripción de la diferencia radical, de la exclusión. El Sujeto surge de la exclusión de la escena originaria que introduce al tercero, cuya función principal consiste en introducir la diferencia sexual.

Lo que caracteriza al deseo sexual, para el yo -construido por identificación con el objeto fascinante que lo encierra en su círculo- es que el dolor está ahí desde el principio. La diferencia sexual inscribe una falta esencial en el ser que pone en marcha un deseo imposible de aplacar.

Más que deseo, un anhelo de aquello que el Sujeto no es.

\section{Femenino / Masculino}

La posición del Sujeto del deseo -el Sujeto del inconsciente-, se hallaría más próxima al saber propio de lo femenino, suponiendo que la fantasía narcisista de plenitud ha debido ser atravesada con la constatación de que no es ella lo que la madre desea.

No es ella, la mujer, quien está destinada a completar a su objeto, cuya imagen perfecta sostuvo su identidad primaria. La consternación -el horror- que el varón experimenta ante la diferencia sexual real, la ausencia, en la madre, de la totalidad, del falo en el que anteriormente creía, puede sin embargo ser soslayada mediante la negación del deseo sexual de la madre, y con él, de su Amor por el padre.

De no existir un Sujeto del deseo sexual en la madre, es decir, si ella no le ama a él, podría retornarse a la anterior armonía.

La castración, la insoportable herida narcisista, que es en cualquiera de sus formas una experiencia de muerte para el yo, podría quedar relegada a la mujer sexuada, de modo que pudiera mantenerse la plenitud perdida en torno a la posesión del otro fascinante -la madre completa, en posesión del falo. 
Pero entonces, y como resultado de esta fórmula, la futura relación sexual deparará al amante el castigo incesante de los celos y el asalto, como a Otelo, de la profunda convicción de que es imposible que ella le ame a él.

\section{Amor y plenitud}

Cuando tiene lugar el enamoramiento, suele ocurrir que el yo reconoce en el objeto amado a su objeto primitivo, destinado a devolverle su antigua plenitud.

Un reconocimiento que podría ser mutuo y que se manifiesta en ciertas miradas enamoradas -arrobadas.

Pero este reconocimiento, quizá inevitable en un primer momento, que produce el espejismo de una identidad especular con el amado, conduce inexorablemente al encuentro sexual y, con él, a la confrontación con la diferencia.

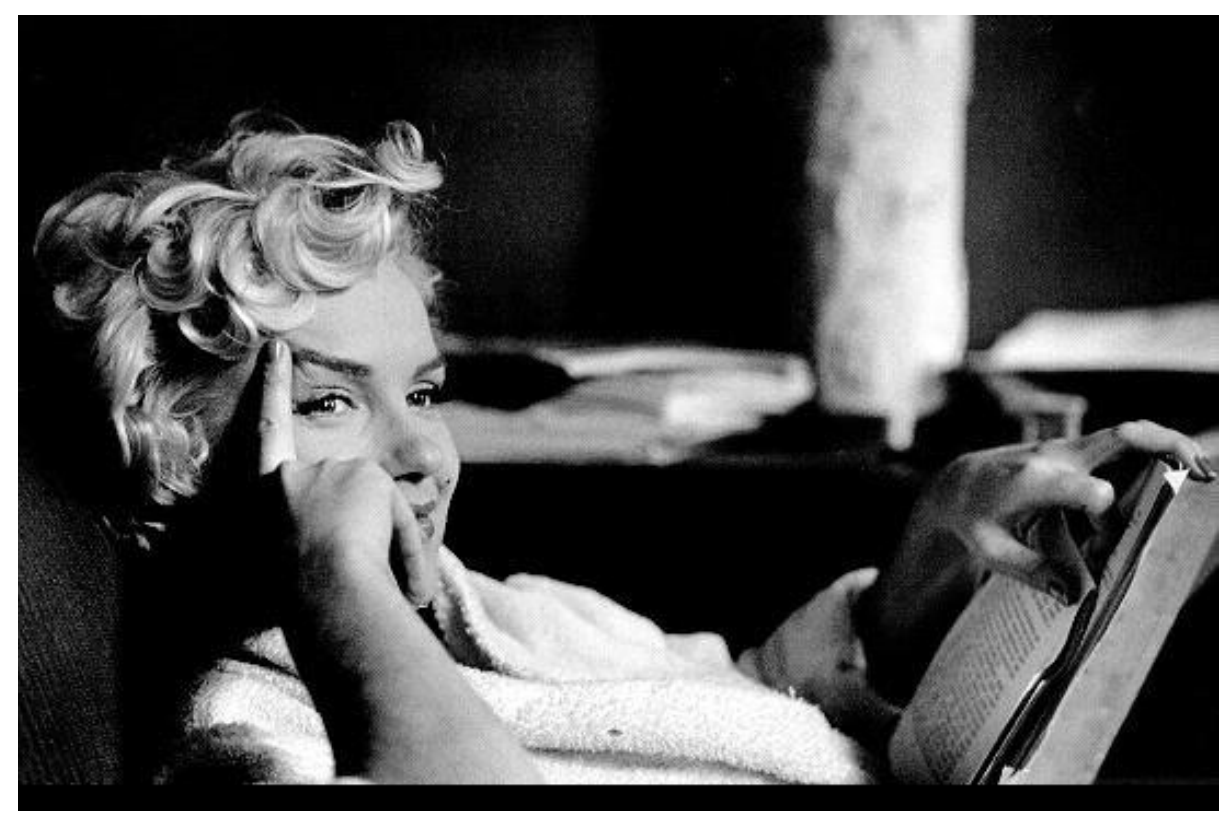

Imagen 10

Cuestiones de género, 2008, $n^{\circ}$ 3, pp 
Para afrontarlo, es precisa la construcción previa de una estructura simbólica de tres posiciones, tres puntos de vista articulados, tres miradas diferentes. Una estructura mítica en tanto originaria del Sujeto y su relato.

Cuando la construcción de la diferencia sexual no ha tenido lugar y la identidad se sustenta sólo en el plano del reconocimiento - del yo- el encuentro sexual es letal. Quizá lo característico de las relaciones abocadas a la violencia o el maltrato sea la captura del ser amado -en posición femenina- en el espejo que le reconoce como objeto fascinante, completo.

Y con ello, la imposibilidad de que el Sujeto en posición femenina conduzca el deseo del amante -la del yo deslumbrado por su objeto- hacia ese más allá del objeto que deparará la herida.

\section{Amor y Dolor}

El amor verdadero, el Amor con mayúscula, sólo empieza tras la renuncia a la posesión, al control absoluto, a la identidad con el objeto. Pero ese amor sólo puede ser vivido por el yo con dolor. La pasión de cada Sujeto, la pasión de Ser, está ligada al saber de ese dolor.

\section{Simbólica de lo femenino}

Es urgente la construcción de una simbólica de lo femenino si pretendemos intervenir en la mejora de las condiciones de posibilidad de las relaciones sexuales. Para este propósito el discurso feminista de la igualdad, imprescindible en otros campos, no nos servirá de ayuda. Y sin embargo, es de enorme importancia lo que está en juego.

Porque si el yo no encuentra frente a sí a un Sujeto que afronte la herida -como el alma del hombre, que siempre ha sido femenina-, y le guíe en la oscuridad del atravesamiento del espejo, el yo del otro -el otro yo- sólo puede convertirse para él en una amenaza, según la lógica dual: o tú o yo, o bien desaparece el otro, o bien 
desaparezco yo. Pero esa lógica es consustancial al espejismo; porque finalmente, los dos desaparecen.

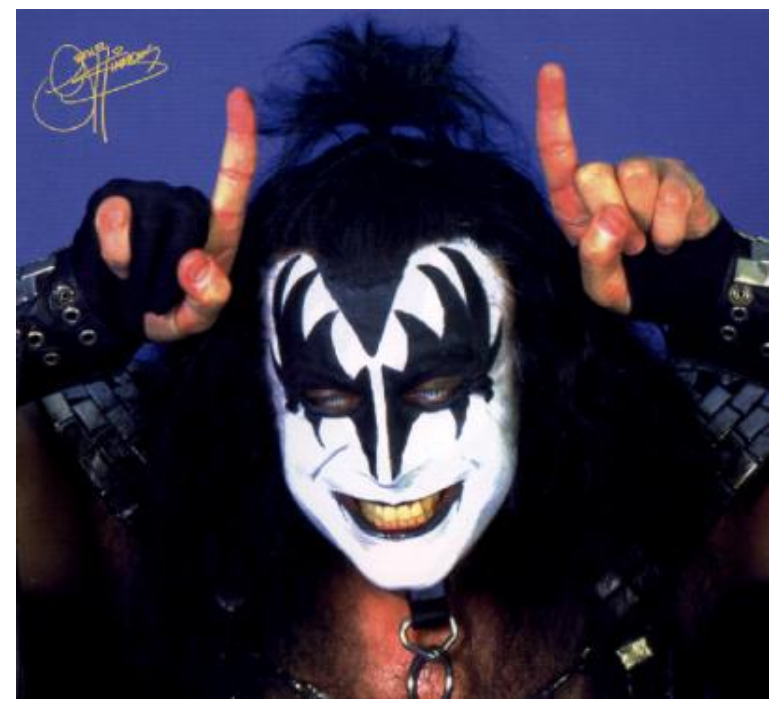

Imagen 11

¿Qué podemos hacer?

En primer lugar, ya lo hemos apuntado, empezar a poner límite, aunque no sea económica ni políticamente rentable a corto plazo, al goce colectivo que se obtiene de la plena disposición para el disfrute del otro -abocado a la humillación.

Por otro, convendría no dejar por el camino de la liberación de las mujeres lo que se supone que hemos aprendido, como colectivo, a lo largo del tiempo:

La necesidad de respetar al otro.

De cuidar a los niños.

De disfrutar con la gentileza de los débiles.

Y servir al amor, cuyo poder es la vida en todas sus formas, incluida la oscuridad que precede a toda forma.

Cuestiones de género, 2008, $n^{\circ}$ 3, pp 


\section{BIBLIOGRAFÍA}

BOIX REIG, J. y MARTÍNEZ GARCÍA, E. (2005) La nueva ley contra la violencia de género Ed. Lustel: Madrid

CÁCERES ZAPATERO, Ma Dolores (2006) “Comunicación y Educación. Un balance cualitativo". Icono $14 N^{\circ} 72006$

FREUD, Sigmund (1919/20) "Más allá del Principio del Placer" Obras Completas. Biblioteca Nueva: Madrid.

—(1923) "El Yo y el Ello". Obras Completas. Biblioteca Nueva: Madrid.

GUIJARRO JIMÉNEZ, A. y cols. (1999) Influencias de la televisión en la infancia y adolescencia (I) Vol. $29 N^{\circ} 272$ pg. 263-269

-(1999) Influencias de la televisión en la infancia y adolescencia (II) Vol. $29 n^{\circ} 273$ pg. 289-293

LACAN, J. (1966) "El estadío del espejo como formador de la función del yo tal como se nos revela en la experiencia psicoanalítica" Écrits. Éditions du Seuil: París. Trad. 1971 Escritos I. Siglo XXI.

—(1966) "La agresividad en psicoanálisis” Écrits. Éditions du Seuil: París. Trad. 1975 Escritos II. Siglo XXI

- (1981) Le Séminaire de Jacques Lacan. Livre III: Les Psychoses. Éditions du Seuil: París. Trad. 1984 El Seminario de Jacques Lacan 3: Las Psicosis Ed. Paidós: Barcelona. (Seminario de 1956).

—(1975) Le Séminaire de Jacques Lacan. Livre XX : Encore, 1972-1973. Éditions du Seuil: París. Trad. 1981: Aun. Paidós: Buenos Aires.

MINISTERIO DE INDUSTRIA, TURISMO Y COMERCIO: Código autorregulación contenidos televisión e infancia. Página web consultada 13-11-07:

http://www.mityc.es/MediosAudiovisuales/Secciones/Contenidos/ProteccionMenor/2.C odigo/

SERRANO GONZÁLEZ, Ma Isabel (Ed) (2002) La Educación para la Salud del siglo XXI: Comunicación y salud. Ediciones Díaz de Santos: Madrid. 
UNIVERSIDAD DE SEVILLA, Universidad Internacional de Andalucía (2005) Violencia Editorial Padilla Libros

ZIMMERMAN, Frederick; CHRISTAKIS, Dimitri; (2005) "Childen's Televisión Viewing and Cognitive Outcomes. A Longitudinal Analysis of National Data" Archives of Pediatrics \& Adolescent Medicine Vol. 159 nº 7 July, pg. 619-625 